\author{
한우의 유전체 육종가의 정확도 추정 \\ 이승수 ${ }^{1} \cdot$ 이승환 $^{1} \cdot$ 최태정 $^{1} \cdot$ 최연호 $^{1} \cdot$ 조광현 $^{1} \cdot$ 최유림 $^{1} \cdot$ 조용민 $^{1} \cdot$ 김내수 $^{2} \cdot$ 이중재 $^{2 *}$ \\ ${ }^{1}$ 농촌진흥청 국립축산과학원, ${ }^{2}$ 충북대학교
}

\title{
Estimation of the Accuracy of Genomic Breeding Value in Hanwoo (Korean Cattle)
}

\author{
Seung Soo Lee ${ }^{1}$, Seung Hwan Lee ${ }^{1}$, Tae Jeong Choi ${ }^{1}$, Yun Ho Choy ${ }^{1}$, Kwang Hyun Cho ${ }^{1}$, You Lim Choi ${ }^{1}$, \\ Yong Min Cho ${ }^{1}$, Nae Soo $\mathrm{Kim}^{2}$ and Jung Jae Lee ${ }^{2 *}$ \\ ${ }^{1}$ National Institute of Animal Science, RDA, ${ }^{2}$ Department of Animal Science, Chungbuk national University Cheongju, \\ Chungbuk, 361-763, Korea
}

\begin{abstract}
This study was conducted to estimate the Genomic Estimated Breeding Value (GEBV) using Genomic Best Linear Unbiased Prediction (GBLUP) method in Hanwoo (Korean native cattle) population. The result is expected to adapt genomic selection onto the national Hanwoo evaluation system. Carcass weight (CW), eye muscle area (EMA), backfat thickness (BT), and marbling score (MS) were investigated in 552 Hanwoo progeny-tested steers at Livestock Improvement Main Center. Animals were genotyped with Illumina BovineHD BeadChip (777K SNPs). For statistical analysis, Genetic Relationship Matrix (GRM) was formulated on the basis of genotypes and the accuracy of GEBV was estimated with 10-fold Cross-validation method. The accuracies estimated with cross-validation method were between $0.915 \sim 0.957$. In 534 progeny-tested steers, the maximum difference of GEBV accuracy compared to conventional EBV for CW, EMA, BT, and MS traits were 9.56\%, 5.78\%, 5.78\%, and 4.18\% respectively. In 3,674 pedigree traced bulls, maximum increased difference of GEBV for CW, EMA, BT, and MS traits were increased as $13.54 \%$, $6.50 \%, 6.50 \%$, and $4.31 \%$ respectively. This showed that the implementation of genomic pre-selection for candidate calves to test on meat production traits could improve the genetic gain by increasing accuracy and reducing generation interval in Hanwoo genetic evaluation system to select proven bulls.
\end{abstract}

(Key words : GBLUP, GEBV, SNP, Cross-validation, Genomic selection)

\section{서 론}

유전체 선발 (Genomic Selection, GS)은 기존 통계육종 방법에 비하여 육종가 추정의 정확도를 높일 수 있으며, 세대간격을 줄이 고, 혈통 오류를 감소시키며, 유전력이 낮은 형질이나 측정하기 어 려운 형질에 대해서도 육종가를 추정할 수 있는 장점이 있다 (Meuwissen 2003). 그러나 유전체 선발의 결과는 마커 효과가 추 정된 참조집단의 크기, 형질의 유전력, 양적형질 유전자좌 (Quantitative Trait Loci, QTL)와 마커 간의 연관 불평형 정도, QTL의 분포형태 및 유효집단의 크기에 좌우되므로 그에 맞는 적 절한 통계 모형과 마커 패널의 선택이 중요하다.

Meuwissen 등 (2001)이 제시한 유전체 선발 방법은 유전체 전 체에 균등하게 분포한 수많은 마커를 이용하여 개체별로 분석한 마 커 유전자형 정보와 표현형 정보를 바탕으로 각 마커 별로 개체의
능력에 기여하는 값을 추정하고, 아직 능력을 모르는 개체를 그 개 체에서 분석한 마커에 따른 효과를 모두 종합하여 이용한다. 이 방 법으로 각 유전변이의 기능이 일일이 확인되지는 않지만 유전체 정 보 수집에 사용된 마커가 형질에 관여하는 모든 양적형질 유전자좌 와 연관이 발생할 정도로 충분히 많고, 유전체 정보와 표현형 정보 를 동시에 가진 개체의 수가 충분할 경우 개체의 유전체 정보만을 이용하여 육종가를 계산해 낼 수 있게 되었다. 이러한 이론을 바탕 으로 SNP(Single Nucleotide Polymorphisms) 마커를 이용하여 홀스타인과 앵거스 품종의 유전능력을 추정하는 연구가 미국, 호주, $\mathrm{EU}$ 국가들에서 활발히 진행되고 있다(Rolf 등, 2010; $\mathrm{Su}$ 등, 2012; VanRaden 등, 2009; Hayes 등, 2009a).

한우에 대한 본격적인 유전체 선발 연구는 모의실험 자료로 형질 에 관여하는 양적형질 유전자좌의 밀도, 마커의 밀도, 참조집단의 크기를 다르게 설정하여 GBULP과 Bayesian 모델에 대한 선발의

* Corresponding author: Jung Jae Lee, Department of Animal Science, Chungbuk national University Cheongju, Chungbuk, 361-763, Korea. Tel: 82-17-434-8052, Fax: 82-43-273-2240, E-mail: 1jj791201@chungbuk.ac.kr 
효율과 정확도를 추정한 바 있으며 (Lee, 2011; Cho and Lee, 2011), 실제 한우 축군에 대한 연구로는 Lee(2012)가 농협 한우개 량사업소 후대검정우 556두에 대해 $50 \mathrm{~K} \mathrm{SNP} \mathrm{chip으로} \mathrm{유전자형}$ 을 분석하여 GBLUP으로 GEBV와 그 정확도를 추정하였다.

본 연구는 실제 한우 축군 (농협 한우개량사업소 후대검정우)에 대해 고밀도 $\mathrm{SNP}$ 패널 $(777 \mathrm{~K})$ 을 사용하여 유전체 혈연 행렬 (Genetic Relationship Matrix, GRM)을 추정하고 GBLUP (Genomic Best Linear Unbiased Prediction) 방법으로 GEBV (Genomic Estimated Breeding Value)를 구하고, 교차 검증 (Cross-validation) 방법으로 그 정확도를 추정함으로써 유전체 선 발 기법을 한우 유전평가 체계에 적용하기 위한 기초자료로 이용하 고자 수행하였다.

\section{재료 및 방법}

\section{1. 분석 자료}

농협중앙회 한우개량사업소에서 2009년부터 2012년 사이에 수 행된 한우개량사업 45차, 46차, 48차 및 49차 후대검정우 총 552 두의 자료를 최종적으로 이용하였고 이에 대한 검정 차수와 월령별 분포를 Table 1에 나타냈었다. 대상 후대검정우의 혈통을 4세대까 지 추적하여 3,674두에 대한 정보를 수집하고, 도체중 (Carcass weight, CW), 배최장근단면적 (Eye Muscle Area, EMA), 등지방 두께 (Backfat Thickness, BT) 및 근내지방도 (Marbling Score, $\mathrm{MS})$ 형질의 표현형을 분석하였다.

유전자형 분석을 위한 시료는 경정맥에서 채혈한 후 Genome Nucleic Acid Purification Kit (MagExtractor ${ }^{\mathrm{TM}}$, Toyobo CO., LTD. Osaka, Japan)로 DNA를 추출하였다. SNP 유전자형 분석 은 Illumina사의 BovineHD BeadChip (777K SNPs)을 이용하였 다. 결정된 유전자형에 대하여 이형접합체와 동형접합체만 존재하 는 경우, 하디-와인버그 평형 (Hardy-Weinberg equilibrium, $\mathrm{HWE}$ )이 극도의 편차를 보이는 경우, 유전자형 결측 비율 (Missing proportion, $\mathrm{MSP}$ )이 $20 \%$ 이상인 경우 및 Minor Allele frequency (MAF)가 0.05 이하인 경우 등을 제외한 총 578,489개 의 SNP 마커를 이용하였다.

Table 1. Number of heads by batch-number and age of month at slaughtering in progeny-tested steers

\begin{tabular}{cccc}
\hline \multicolumn{4}{c}{ Progeny-Tested Steers } \\
\hline Batch-Number & No. & Age (Month) & No. \\
\hline \hline 45 & 119 & 22 & 64 \\
46 & 138 & 23 & 305 \\
48 & 148 & 24 & 183 \\
49 & 147 & & \\
Total & 552 & & 552 \\
\hline
\end{tabular}

\section{2. 통계분석}

\section{(1) 육종가 추정}

각 형질에 대한 개체들의 육종가를 추정하기 위하여 다음과 같이 혼합 선형 모형을 이용하였다.

$\mathrm{Y}=\mathrm{Xb}+\mathrm{Zu}+\mathrm{e}$

$\mathrm{Y}$ 는 형질에 대한 관측치 벡터, $\mathrm{X}$ 는 고정효과(도축 월령, 검정 차 수)에 대한 벡터, $\mathrm{Z}$ 는 개체에 대한 임의효과 벡터, $\mathrm{b}$ 는 고정효과에 대한 추정치 벡터, $\mathrm{u}$ 는 개체에 대한 추정치 벡터, $\mathrm{e}$ 는 임의 오차이 고, $\mathrm{E}(\mathrm{y})=\mathrm{Xb}, \operatorname{Var}(\mathrm{u})=\mathrm{G}=\mathrm{A} \sigma_{a}^{2}, \operatorname{Var}(\mathrm{e})=\mathrm{R}=\mathrm{I} \sigma_{e}^{2}, \operatorname{Cov}(\mu$, $\mathrm{e})=0$ 으로 가정하여 $\operatorname{Var}(\mathrm{y})=\mathrm{V}=\mathrm{ZGZ}+\mathrm{R}$ 가 된다. 여기서 $\mathrm{A}$ 는 개체 간의 혈연계수 행렬, $\sigma_{a}^{2}$ 는 상가적 유전분산, $\sigma_{e}^{2}$ 는 임의 오차 분산이다.

\section{(2) 유전체 육종가 추정}

계산의 효율을 높이기 위해 578,489개의 SNP 마커에 대해 조사 된 4가지 형질에서 최소제곱법을 이용하여 $\mathrm{SNP}$ 마커의 효과를 추 정하고, 우도비 검정 (Likelihood Ratio Test)를 통하여 5\% 유의 적인 수준의 임계치 3.84 이상인 $\mathrm{SNP}$ 마커만 선별하여 분석에 이 용하였다.

최소제곱법으로 유전체 마커의 효과를 추정하고 이것으로 개체에 대한 유전체 육종가를 추정할 경우 과대 추정 (over-estimation)되 는 문제점이 발생하므로 $\mathrm{SNP}$ 마커 효과의 분산 값이 동일하다는 가정 하에 $\mathrm{SNP}$ 마커의 효과를 평균에 맞추어 보정하기 위하여 능 형회귀를 이용한 BLUP (Ridge Regression Best Linear Unbiased Prediction, RR-BLUP) 방법으로 추정하였다(Meuwissen et al., 2001; Whittaker ar al., 2000). 이 방법은 유전체 전체에 매우 많 은 유전자가 고르게 분포하고 있으며 이들이 형질에 작은 효과로 동일하게 기여한다는 무한소 모형 (Infinitesimal Model)을 기반으 로 하며 (Hayes et al., 2009a; Visscher et al., 2006), 모든 SNP 마커 효과의 합이 추정 유전체 육종가 (Genomic estimated breeding value, GEBV)가 된다. 통계 모형식은 다음과 같다.

$$
y=X b+\sum_{i=1}^{N} Z_{i} g_{i}+e
$$

$b$ 는 고정효과(도축 월령 및 검정 차수)에 대한 벡터, $g_{i}$ 는 $\mathrm{i}$ 번째 마커의 효과, $N$ 은 전체 $\mathrm{SNP}$ 마커의 수, $X, Z$ 는 각각 $b$ 와 $g$ 에 대 한 계수 행렬, $e$ 는 잔차 오차에 대한 벡터이다. 개체별 유전체 육 종가는 다음과 같이 추정하였다.

$$
G E B V=X \hat{g}
$$

$\hat{g}$ 는 추정된 마커의 효과이며, 가우스-자이델 반복법(Gauss- 
Seidel iteration)을 이용하여 추정하였으며, 반복 횟수를 1,000 번 수행하여 수렴을 $1.0 \mathrm{E}-8$ 수준 이하로 설정하였다.

\section{(3) 유전체 혈연 행렬 추정}

유전체 혈연 행렬을 추정하기 위해 대립유전자의 빈도를 이용하 여 추정하는 Allele Frequency Method $(\mathrm{GOF})$ 과 유전자형 분석이 완료된 개체와 분석되지 않은 개체들을 혼합하여 혈연 관계를 추정 하는 방법(Combined Pedigree and Genomic Relationship Method : H)을 사용하였다.

$\mathrm{GOF}$ 는 대립인자의 평균 효과를 0 으로 할당하는 방법(VanRaden, 2008)으로 개체 수를 $\mathrm{n}$ 으로, 이용된 $\mathrm{SNP}$ 마커 수를 $\mathrm{m}$ 으로 설정 하고, 이를 $\mathrm{M}$ 행렬로 표기한다. $\mathrm{M}$ 행렬의 크기는 $\mathrm{n} \times \mathrm{m}$ 으로 설정 되며 유전체 혈연 행렬 추정 식은 다음과 같다.

$$
G=\frac{(M-P)(M-P)^{\prime}}{2 \sum_{j=1}^{m} P_{j}\left(1-P_{j}\right)}
$$

여기서, $\mathrm{M}$ 행렬의 원소를 첫 번째 대립인자에 의한 동형접합체 (11)의 경우는 0 , 이형접합체 (12)의 경우는 1 그리고 두 번째 대 립인자에 의한 동형접합체(22)의 경우는 2로 정의한다. $\mathrm{MM}^{\prime}$ 행렬 은 $\mathrm{n} \times \mathrm{n}$ 의 크기로 설정되고 대각의 원소들은 해당 개체의 동형접합 체의 수를 나타내며 비대각의 원소들은 두 개체들 간에 공통으로 갖는 대립 인자의 수가 되고 $\mathrm{P}$ 는 두 번째 대립인자 빈도(혹은 Minor Allele Frequency)를 포함하며 $2 \mathrm{p}_{\mathrm{j}}$ 로 표현된다.

유전체와 가계 정보가 통합된 혈연 행렬의 추정 방법은 다음과 같은 식을 기반으로 사용하였다(Misztal 등, 2009).

$$
H=\left[\begin{array}{cc}
A_{11} & A_{12} \\
A_{21} & G
\end{array}\right]=A+\left[\begin{array}{cc}
0 & 0 \\
0 & G-A_{22}
\end{array}\right]
$$

여기서, 첨자 1 과 2 는 각각 $\mathrm{SNP}$ 마커에 대한 유전자형 분석이 완료된 개체와 분석이 되지 않은 개체를 나타내며, $\mathrm{G}$ 는 위에서 설 명되었던 유전자형 빈도를 이용하여 추정된 유전체 혈연 행렬을 의 미한다.

(4) 유전체 육종가 정확도 추정

RR-BLUP 방법을 이용하여 추정된 유전체 육종가의 정확도를
추정하기 위하여 참조 집단 (Reference Set)으로부터 추정된 SNP 마커의 효과 및 고정 효과를 검정 집단(Validation Set)에 적용한 후 검정 집단의 표현형가와 유전체 육종가 간의 상관을 추정하는 교차 검증(Cross-validation) 방법을 이용하였다. SNP 유전자형 분석이 완료되고 도체성적이 있는 후대검정우 552두 중에서 무작 위적으로 502 두 $(90 \%)$ 를 참조 집단으로 선별하여 RR-BLUP 방법 으로 각 형질 별로 유의한 $\mathrm{SNP}$ 마커 세트에 대하여 SNP 마커의 효과 및 고정효과를 동시에 추정하였다. 그리고 나머지 50두 (10\%) 는 검증 집단으로 설정하여 $\mathrm{GEBV}$ 를 추정하였으며 이와 같은 작 업을 10 반복 수행하였다. 그리하여 검증 집단 개체들의 표현형가와 추정된 $\mathrm{GEBV}$ 간의 상관을 통하여 정확도를 추정하였다.

혈연 행렬을 이용하여 추정된 유전체 육종가에 대한 정확도는 직 접적인 역행렬 계산을 통하여 정확한 예측 오차 분산(Exact Predicted Error Variance, $\mathrm{PEV}_{\text {exact }}$ )을 추정하여 이용하였다.

본 연구의 분석을 위하여 PC 용 SAS Package (Version 9.1)와 포트란 코드로 작성된 알고리듬 프로그램을 이용하였다. 작성된 포 트란 코드는 Intel Visual Fortran Compiler(Window Ver. 11.1) 를 이용하여 윈도우 버전에서 컴파일하였다.

\section{결과 및 고찰}

본 연구에서 조사된 후대검정우 552두에 대한 도체중, 배최장근 단면적, 등지방두께 및 근내지방도의 기초통계량을 Table 2에 표시 하였다. 후대검정우의 도체중, 배최장근단면적, 등지방두께 및 근내 지방도의 평균 및 표준편차는 각각 $352.99 \pm 37.83 \mathrm{~kg}, 82.35 \pm 8.30$ $\mathrm{cm}^{2}, 7.99 \pm 3.08 \mathrm{~mm}$ 그리고 $3.05 \pm 1.47$ 점으로 추정되었다. 본 연구 에서 추정된 평균치는 Hwang 등 (2008)이 후대 검정우 23차에서 40차까지 2,791두의 자료에 대하여 추정한 평균치인 $321.01 \pm 41.89 \mathrm{~kg}, 75.72 \pm 8.19 \mathrm{~cm}^{2}, 8.27 \pm 3.69 \mathrm{~mm}$ 및 $2.91 \pm 1.63$ 점보다 다소 높게 추정되었으며, $\mathrm{Kim}$ 등 (2010)이 36차부터 40차 까지 734 두의 후대 검정우에 대하여 보고한 $356.5 \pm 38.2 \mathrm{~kg}$, $77.7 \pm 8.2 \mathrm{~cm}^{2}, 10.3 \pm 4.0 \mathrm{~mm}$ 및 $3.3 \pm 1.7$ 점과는 비슷한 경향을 나 타내었다.

최소제곱법으로 SNP 마커의 효과를 추정하여 유의한 SNP 마커 만 선택한 것은 표현형 자료를 가진 552두에 대해 4개 형질별로 578,489 개의 SNP 마커의 효과를 동시에 추정하는 것이 상당한 연 산량을 요구하므로 이후 추정의 효율성을 높이기 위하여 수행하였

Table 2. Descriptive statistics of traits for 552 progeny-tested streers

\begin{tabular}{crrrr}
\hline Traits & Mean & S.D. & Min. & Max. \\
\hline \hline CW $(\mathrm{kg})$ & 352.99 & 37.83 & 183 & 465 \\
EMA $\left(\mathrm{cm}^{2}\right)$ & 82.35 & 8.30 & 60 & 111 \\
BF $(\mathrm{mm})$ & 7.99 & 3.08 & 23 & 2 \\
MS & 3.05 & 1.47 & 1 & 9 \\
\hline
\end{tabular}

CW: Carcass weight; EMA: Eye Muscle Area; BT: Backfat Thickness; MS: Marbling score 
다. 조사된 각각의 형질에서 적합도 검정을 통하여 유의적인 효과 를 가지는 걸로 추정된 SNP 마커는 총 578,489 개의 SNP 마커 중에서 도체중 50,632 개, 배최장근단면적 50,435 개, 등지방두께 67,213 개 및 근내지방도 46,592 개였다.

본 연구와 같이 SNP 마커의 효과를 추정하는 집단의 크기가 상 대적으로 작고 따로 검증 집단을 조성하지 못한 경우, 육종가 추정 의 정확도를 계산하기 위한 방법으로 임의 소포본집단 반복추출 (random subsampling replication)을 이용한 10반복 교차 검증 (10-fold cross validation) 방법을 이용하였다. 표현형과 유전자형 자료가 있는 후대검정우 552두 중에서 무작위적으로 502두 (90\%) 를 참조 집단으로 추출하여 각 형질 별로 유의한 $\mathrm{SNP}$ 마커 세트 에 대하여 $\mathrm{SNP}$ 마커의 효과 및 고정효과를 동시에 추정한 후 나 머지 50 두 $(10 \%)$ 는 검증 집단으로 설정하여 $\mathrm{GEBV}$ 를 추정하여 이 미 알고 있는 검증 집단 개체들의 표현형가와 추정된 $\mathrm{GEBV}$ 간의 상관을 통하여 정확도를 추정한 결과를 Table 3에 나타내었다. 각 형질별로 추정된 정확도의 결과를 살펴보면, 유전체 육종가의 정확 도가 형질별로 0.915 0.957로 상당히 높게 추정되었다. 그러나 이 러한 결과는 유전체 선발에 의한 결과로 해석되기 보다는 현재 SNP 마커들에 대한 효과를 RR-BLUP 방법에 의하여 추정된 것 이 얼마나 정확한 것인지 판단하는 기준으로 유효한 것으로 사료된 다. 타 문헌에 의하면 reference와 validation data set 간의 혈연 관계는 유전체 예측의 정확도에 영향을 주며, 두 data set간의 혈 연관계가 높을수록 정확도가 높아지게 된다(Clack et al., 2012). 이와 비슷한 결과가 예측(Hayes et al., 2009b) 및 관측되었다 (Habier et al., 2007; Habier et al., 2010). 본 연구에 이용된 reference 집단이 후대 검정우로서 혈연관계가 상당히 높기 때문에 (유전체 기반의 최대 혈연 계수 : 0.4304 , 가계 기반의 최대 혈연 계수 : 0.3926) 위와같은 결과가 추정된 것으로 사료된다.
유전체 혈연 행렬을 비교하여 혈통 오류를 제거한 534 두에 대하 여 가계 정보로 계산된 혈연 행렬을 이용한 혼합 모형식으로 추정 된 BLUP 방법과 위의 혼합 모형식에 기존의 혈연 행렬 대신에 유 전체 혈연 행렬로 대치하여 추정한 GBLUP 방법 간에 육종가의 정확도의 평균울 Table 4에 나타내었다. 대립인자의 빈도를 이용하 여 추정된 유전체 혈연 행렬 $(\mathrm{GOF})$ 과 기존의 혈연 행렬과 통합된 유전체 혈연 행렬 $(\mathrm{H})$ 을 이용한 육종가의 정확도 평균이 각 형질별 로 차이를 나타낸 것은 형질별로 다른 분산 성분(환경 분산과 유 전 분산)을 가지고 있기 때문이며, 추정된 유전력은 도체중, 배최장 근 단면적, 등지방두께 및 근내 지방도에 대하여 각각 $0.50,0.41$, 0.40 및 0.50 으로 추정되었다. 특히 근내 지방도 형질의 경우 모든 혈연 행렬에 대하여 가장 높은 유전 모수로 추정되었기 때문에 정 확도의 평균 역시 가장 높게 추정되었다.

Table 5에는 표현형 자료를 갖고 있으며 SNP 유전자형 분석이 완료된 개체 534두(후대검정우)와 혈연관계가 조사된 3,674두에 대해 유전체 혈연 행렬들을 이용하여 추정된 GBLUP 방법과 가계 정보를 기반으로 계산된 혈연 행렬을 이용하여 추정된 BLUP 방법 간에 육종가의 정확도 평균의 차이와 개체별로 육종가의 정확도 차 이가 가장 크게 나타낸 값들을 퍼센트로 변환하여 표시하였다. 대 립유전자의 빈도로 계산된 유전체 혈연 행렬을 이용하여 GBLUP 방법으로 추정된 육종가 정확도 평균은 기존의 BLUP 방법으로 추 정된 육종가 정확도 평균보다 후대검정우 534두에 대하여 $0.51 \%$ $\sim 1.28 \%$ 정도의 정확도 상승을 나타내었으며, 혈통 기록상의 모든 개체 3,674 두를 대상으로는 $0.57 \% ~ 1.29 \%$ 수준으로 비슷한 값을 나타내었다. 그러나 육종가 정확도의 최대 차이는 후대검정우 534 두에 대하여 도체중, 배최장근 단면적, 등지방 두께 및 근내지방도 순으로 각각 $9.56 \%, 5.78 \%, 5.78 \%$ 및 $4.18 \%$ 정도의 수준으로 상승했고, 혈통 기록상의 모든 개체 3,674두에 대해서는 형질 별로

Table 3. Mean accuracy of GEBV in the validation sets using 10-fold cross-validation method

\begin{tabular}{cccc}
\hline \multirow{2}{*}{ Traits } & \multicolumn{3}{c}{ 10-Fold Cross validation } \\
\cline { 2 - 4 } & No. of SNP marker & Mean accuracy & S.D. \\
\hline \hline CW & 51,680 & 0.915 & 0.0060 \\
EMA & 47,394 & 0.950 & 0.0011 \\
BF & 65,264 & 0.925 & 0.0113 \\
MS & 45,134 & 0.957 & 0.0035 \\
\hline
\end{tabular}

CW: Carcass weight; EMA: Eye Muscle Area; BT: Backfat Thickness; MS: Marbling score

Table 4. Average accuracies of breeding value for traits using BLUP and GBLUP

\begin{tabular}{cccccc}
\hline Population & Analysis & CW & EMA & BF & MS \\
\hline \hline $\begin{array}{c}\text { Steers } \\
(534)\end{array}$ & A (BLUP) & 0.6047 & 0.6748 & 0.6748 & 0.7364 \\
\hline Total & GOF (GBLUP) & 0.6176 & 0.6812 & 0.6812 & 0.7416 \\
$(3,674)$ & A-matrix (GLUP) & 0.2550 & 0.2838 & 0.2838 & 0.3089 \\
\hline
\end{tabular}


Table 5. Comparison with mean difference and maximum difference of accuracies between BLUP and GBLUP from combined relationship matrix for traits

\begin{tabular}{cccccc}
\hline \multirow{2}{*}{ Accuracy } & & \multicolumn{3}{c}{ Traits } \\
\cline { 3 - 6 } & & CW & EMA & BF & MS \\
\hline \hline \multirow{2}{*}{ Mean Difference (\%) } & Steers $^{1)}$ & 1.28 & 0.64 & 0.64 & 0.51 \\
& Total $^{2)}$ & 1.29 & 0.81 & 0.81 & 0.57 \\
\hline \multirow{2}{*}{ Maximum Difference (\%) } & Steers & 9.56 & 5.78 & 5.78 & 4.18 \\
& Total & 13.54 & 6.50 & 6.50 & 4.31 \\
\hline
\end{tabular}

${ }^{1)}$ Steers are 534 heads; ${ }^{2)}$ Total is 3,674 heads.

최대 $13.54 \%, 6.50 \%, 6.50 \%$ 및 $4.31 \%$ 정도의 수준으로 증가한 결과가 추정되었다.

이는 Forni 등 (2011)이 SNP 마커에 대한 유전자형 분석이 완 료된 개체들에 대한 육종가의 정확도 평균을 여러 가지 혈연 행렬 에 따라서 추정했을 때, 혈통 기록에 의한 혈연 행렬을 이용하여 추정된 육종가의 정확도 평균이 낮았을 경우에는 유전체 혈연 행렬 을 사용하여 추정된 유전체 육종가의 정확도 평균이 $6 \%$ 27\% 수 준으로 상당히 상승되는 효과를 나타내었으나, 이미 상당히 높은 육종가의 정확도로 추정된 집단의 경우에는 유전체 혈연 행렬을 사 용하여 유전체 육종가를 추정하여도 정확도 평균의 상승폭이 $1 \%$ $\sim 4 \%$ 수준으로 적게 나타난 결과가 본 연구의 결과와 일치한다. 또 한 Lee 등 (2012)은 한우의 성장형질을 조절하는 유전자의 효과 및 분포는 큰 유전자의 효과라기보다는 보통의 효과를 갖는 유전자 와 아주 작은 효과를 갖는 많은 유전자에 의해 조절되므로 유전체 선발 시 유용한 정보를 제공할 것이라고 했다. 이는 한우 유전능력 평가사업에서 아직 주요 경제형질에 대하여 표현형 자료를 생산할 수 없는 당대검정 후보축 대한 집단을 조성할 때 기존의 혈연정보 뿐만이 아니라 유전체 정보를 이용한 사전 선발을 활용하게 된다 면, Forni 등 (2011)의 인용문헌에서 제시한 바와 같이 전통 $\mathrm{BLUP}$ 을 통하여 추정된 육종가의 정확도가 상대적으로 낮았을 경 우 유전체 정보를 활용할 경우 정확도의 상승폭이 높아질 뿐만 아 니라, 세대 간격을 단축하여 유전적 개량량을 극대화 할 수 있을 것으로 기대된다.

\section{요 약}

본 연구는 농협 한우개량사업소 후대검정우 552 두의 도체중, 배 최장근단면적, 등지방두께 및 근내지방도를 측정한 후 고밀도 $\mathrm{SNP}$ 패널 $(777 \mathrm{~K})$ 을 사용하여 유전체 혈연 행렬(Genetic Relationship Matrix, GRM)을 추정하고 GBLUP(Genomic Best Linear Unbiased Prediction) 방법으로 GEBV(Genomic Estimated Breeding Value)를 구하여 교차 검증 (Cross-validation) 방법으로 그 정확도를 추정함으로써 유전체 선발 기법을 한우 유전평가 체계 에 적용하기 위한 기초자료로 이용하고자 수행하였다. 교차 검증 방법으로 각 형질별로 추정된 유전체 육종가의 정확도는 0.915
0.957로 상당히 높게 추정되었다. 대립유전자의 빈도로 계산된 유 전체 혈연 행렬을 이용하여 GBLUP 방법으로 추정된 육종가 정확 도의 최대 차이는 후대검정우 534두에 대하여 도체중, 배최장근 단면적, 등지방 두께 및 근내지방도 순으로 각각 $9.56 \%, 5.78 \%$, $5.78 \%$ 및 $4.18 \%$ 정도의 수준으로 상승했고, 혈통 기록상의 모든 개체 3,674 두에 대해서는 형질 별로 최대 $13.54 \%, 6.50 \%, 6.50 \%$ 및 $4.31 \%$ 정도의 수준으로 증가한 결과가 추정되었다. 이는 한우 보증씨수소의 선발 시스템에서 아직 표현형 자료를 생산할 수 없는 당대검정 후보축 대한 집단을 조성할 때 유전체 정보를 이용한 사 전 선발을 활용하면 기존의 상대적으로 낮았던 육종가의 정확도의 상승 효과와 세대 간격의 단축으로 인하여 유전적 개량랑을 증대시 킬 수 있을 것으로 기대된다.

본 연구에서 genomic breeding value 추정을 위하여 조성된 집 단의 경우는 후대 검정우 집단으로서 개체들 간의 혈연관계가 높으 며, 이미 전통적인 BLUP 방법으로도 상당히 높은 정확도를 가진 집단을 이용하였다. 그러나, 현재 한우 집단에 대한 유전체 자료 구축 시 이용할 수 있는 정확한 자료는 후대검정우 집단 외에는 참 조 집단을 조성할 수 있는 대안이 없으므로, 지속적인 유전체 검정 을 위해서는 다양한 유전적 조성이 구축된 참조 집단을 구축해야 할 것으로 사료된다. 또한 유전체 검정을 통한 정확도 상승효과를 기대하기 위해서 지속적으로 참조 집단의 크기를 늘릴 필요성이 있다.

(주제어 : GBLUP, GEBV, SNP, 교차 검증, 유전체 선발)

$$
\text { 사 사 }
$$

본 연구는 농촌진흥청 차세대 바이오그린 21사업(과제번호: PJ008188)의 지원을 받아 수행되었으며 이에 감사를 드립니다.

\section{인 용 문 헌}

Cho, C. I. and Lee, D. H. 2011. Study on Genetic Evaluation using Genomic Information in Animal Breeding - Simulation Study for Estimation of Marker Effects. J. Anim. Sci. Tech. (Kor.) 53(1):1-6. 
Forni, S., Aguilar, I. and Misztal, I. 2011. Different genomic relationship matrices for single-step analysis using phenotypic, pedigree and genomic information. Genetics Selection Evolution. 43:1.

Habier, D, Tetens, J., Seefried, F. R., Lichtner, P. and Thaller, G. 2010. The impact of genetic relationship information on genomic breeding values in German Holstein cattle. Genetics Selection Evolution. 42:5.

Habier, D., Fernando, R. L. and Dekkers, J. C. M. 2007. The impact of genetic relationship information on genome-assisted breeding values. Genetics. 177:2389-2397

Hayes, B. J., Bowman, P. J., Chamberlain, A. C., Verbyla, K. and Goddard, M. E. 2009a. Accuracy of genomic breeding values in multi-breed dairy cattle popilations. Genetics Selection Evolution. 41:51.

Hayes, B. J., Visscher P. M. and Goddard, M. E. 2009b. Increased accuracy of artificial selection by using the realized relationship matrix. Genet Res. 91:47-60.

Hwang, J. M., Kim, S. D., Choy, Y. H., Yoon, H. B. and Park, C. J. 2008. Genetic Parameter Estimation of Carcass Traits of Hanwoo Steers. J. Anim. Sci. Tech. (Kor.) 50(5):613-620.

Kim, H. S., Hwang, J. M., Choi, T. J., Park, B. H., Cho, K. H., Park, C. J, and Kim S. D. 2010. Research on the Reformation of the Selection Index for Hanwoo Proven Bull. J. Anim. Sci. Tech. (Kor.) 52(2):83-90.

Lee, J. H. 2011. Study on Methodology for Estimating Breeding Values using Genomic Information. Ph. D. thesis, Hankyoung National University.

Lee, J. J. 2012. Genetic Evaluation for Carcass Traits of Hanwoo using Pedigree and SNP Marker-Derived Relationship Matrix. Ph. D. thesis, Chungbuk National University.

Lee, S. H., Lim D. J., Jang, G. W., Cho, Y. M., Choi, B. H., Kim S. D., Oh S. J., Lee J. H., Yoon D. H., Park E. W., Lee, H. K., Hong, S. K. and Yang B. S. 2012. Genome Wide Association Study to Identity QTL for Growth Traits in Hanwoo. J. Anim. Sci. Tech. (Kor.) 54(5):1-10.

Meuwissen, T. 2003. 'Genomic Selection : the future of marker assisted selection and animal breeding'. FAO.

Meuwissen, T. H. E., Hayes, B. J. and Goddard, M. E. 2001. Prediction of Total Genetic Value Using Genome-Wide Dense Marker Maps. Genetics. 157: 1819-1829.

Misztal, I., Legarra, A. and Aguilar, I. 2009. Computing procedures for genetic evaluation including phenotypic, full pedigree, and genomic information. J. Dairy Sci. 92:4648-4655.

Rolf, M. M., Taylor, J. F., Schnabel, R. D., Mckay, S. D., Mcclure, M. C., Northcutt, S. L., Kerley, M. S. and Weaber, R. L. 2010. Impact of reduced marker set estimation of genomic relationship matrices on genomic selection for feed efficiency in Angus cattle. BMC. Genetics 11:24

SAS Institute Inc. 2004. SAS OnlineDoc ${ }^{\circledR}$ 9.1.3. Cary, NC: SAS Institute Inc.

Su, G., Brondum, R. F., Ma, P., Guldbrandtsen, B., Aamand, G. P. and Lund, M. S. 2012. Comparison of genomic predcitions using medium-density $(\sim 54,000)$ and high-density $(\sim 777,000)$ single uncleotide polymorphism marker panels in Nordic Holstein and Red Dairy Cattle populations. J. Dairy Sci. 95:4657-4665.

VanRaden, P. M. 2008. Efficient methods to compute genomic predictions. J. dairy sci. 91:4414-4423.

VanRaden, P. M., Van Tassell, C. P., Wiggans, G. R., Sonstegard, T. S., Schnabel, R. D., Taylor, J. F. and Schenkel, F. S. 2009. Reliability of genomic predictions for North American Holstein bulls. J. Dairy Sci. 92:16-24.

Visscher, P. M., Medland, S. E., Ferreira, M. A., Morley, K. I., Zhu, G., Cornes, B. K., Montgomery, G. W. and Martin, N. G. 2006. Assumption-free estimation of heritability from genome-wide identity-by-descent sharing between full siblings. PLOS Genetic 2(3):e41.

Whittaker, J. C., Thompson, R. and Denham, M. C. 2000. Marker-assisted selection using ridge regression. Genetical Research. 75:249-252.

(Received Jan. 28, 2013; Revised Feb. 25, 2013; Accepted Feb. 26, 2013) 